\title{
Primary Navigation Purpose of Petroglyphs: Reconstruction on the Basis of the Gnomon
}

\author{
Alina Nikolaevna Paranina, Roman Viktorovich Paranin \\ Herzen State Pedagogical University of Russia, St. Petersburg, Russia \\ Email: galina_paranina@mail.ru
}

How to cite this paper: Paranina, A.N. and Paranin, R.V. (2017) Primary Navigation Purpose of Petroglyphs: Reconstruction on the Basis of the Gnomon. Open Access Library Journal, 4: e3811. https://doi.org/10.4236/oalib.1103811

Received: July 6, 2017

Accepted: July 31, 2017

Published: August 3, 2017

Copyright $\odot 2017$ by authors and Open Access Library Inc.

This work is licensed under the Creative Commons Attribution International License (CC BY 4.0).

http://creativecommons.org/licenses/by/4.0/ c) (i) Open Access

\begin{abstract}
The rational functions of primitive art are considered in the article. The reconstruction of the algorithm for the creation and use of petroglyphs as a marking of solar calendars and sundials with the help of an ancient astronomical instrument-gnomon is proposed. Standard geographic methods and observations of the shadow of objects were used in the study. To calculate the shadow charts, the basic trigonometric function and the astrocalculator were used. According to the results of the study, the following conclusions have been formulated: 1 . The basis for constructing images is made up of graphic signs that reflect the movements of light; 2 . The tool for marking the drawings could be a shadow of vertical objects and a rope; 3 . To create the calendar, the most stable natural material-stone-was used, as well as noticeable elements of its heterogeneity-cracks and forms of relief.
\end{abstract}

\section{Subject Areas}

Archaeology

\section{Keywords}

Cultural Heritage, Ancient Navigation Technologies, Petroglyphs of Karelia

\section{Introduction}

In all regions of the world, elements of the structure associated with orientation in space-time, conventionally called sanctuaries, have been identified on objects of cultural heritage and archaeological sites [1] [2]. The level of development of navigation in the $4-6$ century AD in the North is represented by the White Sea petroglyphs (North-West of Russia, Karelia)-boats with a capacity of up to 20 people, scenes of marine fishing (Figure 1).

Obviously, in the open sea, the lack of landscape landmarks involves the use of 


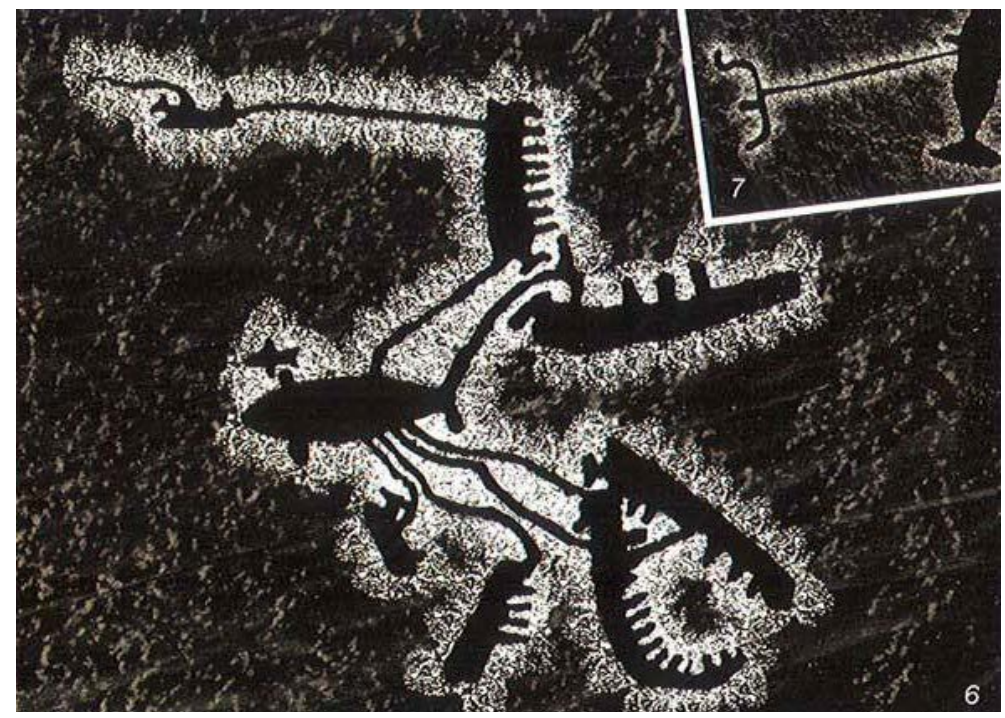

Figure 1. White Sea petroglyphs (river Vyg) ([3], p. 82).

technical navigation tools, and polar days and white nights contribute to the development of the orientation by the sun.

Navigation knowledge of ancient Karelians was studied in the twentieth century on the example of the Petroglyphs of Onega Lake (Karelia). These objects are well studied and documented. It is possible to find the detailed description and the art criticism analysis in classical works of Yu.A. Savvateev [4]. According to N. Lobanova [5], here, out of 1221 images, 184 are solar and lunar signs (Figure 2(a)). According to calculations by F.V. Ravdonikas [6], the azimuths of these signs are associated with the astronomically significant azimuths of the sunrises and sunsets (Figure 2(b)). Analysis of the multilayered images showed that the surface was filled with drawings starting with astronomical signs.

Archaeologist T.M. Potemkina [7] suggested that the lines were drawn on the rocks as continuations of the paths of light observed on the water surface at the time of passage of the horizon lineby the disk of the Sun/Moon. However, this version does not explain the fixation of directions with an accuracy of $1^{\circ}$. In this article, the author's reconstruction of astronomical marking and navigational use of petroglyphs with the help of a gnomon, the oldest astronomical instrument, is proposed.

Our research has shown that the use of the gnomon in the reconstruction of the purpose and semantics of the sites of the ancient heritage is very effective [8]-[13]. For example, the shadow of the gnomon explains the primary navigational purpose of the White Sea labyrinths, some of which were created simultaneously with petroglyphs of Karelia (4 - 6 thousand years ago). All elements of the labyrinth can perform functions of the solar calendar: the diameters of the arcs mark the positions of the noonday shadow of the gnomon, corresponding to the movement of the Sun during the year; Radial marking (entrance, ends of spirals) fixes the boundaries of the astronomical seasons of the year in the azimuths of the shade at sunrise/sunset. The largest number of instrumental 


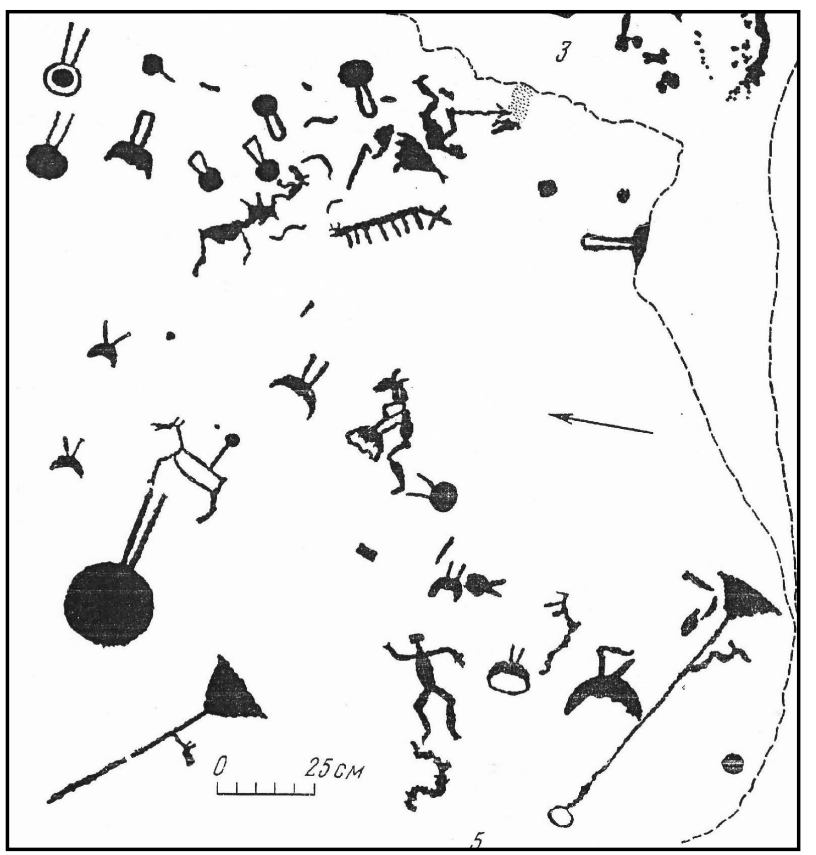

(a)

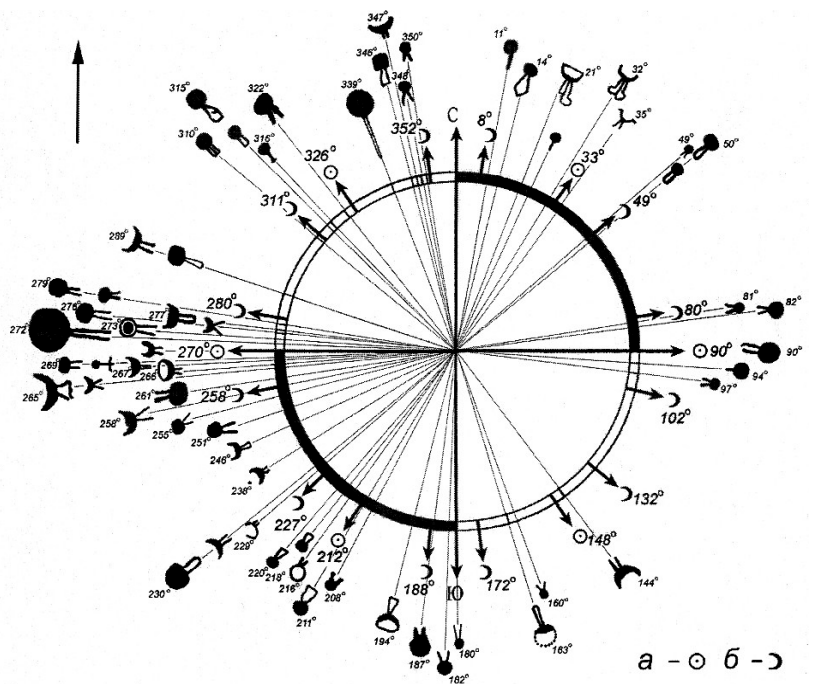

(b)

Figure 2. Onega petroglyphs: (a) fragment of images [4]; (b) correlation of directions of signs and significant azimuths of astronomical objects: the Moon-J, the Sun-( [6].

functions is performed by a double-spiral labyrinth oriented along the meridian, and the whole variety of patterns of labyrinths is explained by the influence of a complex of factors: geographical latitude, horizon shape, astronomical situation at the time of creation, specifics of the phenological cycle, economic tasks and cultural traditions.

The sequence of drawing, specific to petroglyphs, "from geometric signs to an artistic image" is in good agreement with the results of our studies of the semiotic productivity of the gnomon. As an example, we will consider a scheme for drawing shadows on the days of solstices and equinoxes (Figure 3). 


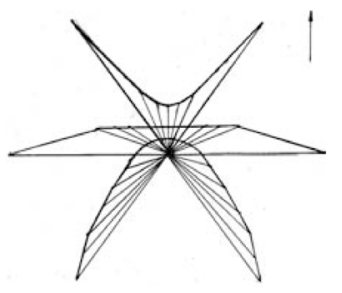

A-winter solstice: the shadows lie in the northern sector of the site, because sunrises/sunsets occur in the southern half of the horizon;

B-spring and autumn equinox: the shadows form a line W-E;

C-summer solstice: shadows cover the southern sector of the site

Figure 3. Schemes of areas covered with a shadow (gnomon-the point in the center) [13].

Analysis of the geometry of the shadow suggests a possible algorithm for encoding information "light movement-geometric sign-image (artistic interpretation of the sign)." The diagram shows that the chart of the shadow of one day can be the basis of zoomorphic images: the tail fin of fish (the line of shadows is the rays), the wings (lines are feathers), horns (lines-annual increment). In the days of solstices and equinoxes, the geometric basis of solar signs (radial and triangular) and six-armed Shiva is created; a more frequent drawing (for example, once a month) gives the image of the multi-armed Shiva or the shape of the open lotus. During the year, the shadow covers an area in the form of a labrys (two-sided, two-legged ax).

It is worth mentioning that the sketch of the shadow of the T- and L-shaped objects provides solar signs in the form of a swastika and once a day forms a straight line (on a polar day-two times). When installing such items crossbar along the meridian (similar to Christian crosses), the direct shape of the shadow indicates north and noon. In ancient times, the functions of the gnomon could be performed by T-shaped megaliths and staffs with a L-shaped top, for example: the taula of Minorca Island in the arch, the Bolero Islands, aged about 3000 years; T-shaped stele of Gebekli-Tepe in Turkey, 11,500 years; curved tops of the staffs of Olenostrovsky burial grounds of Karelia and Murmansk region, aged from 3000 to 10,000 years [13].

The purpose of this study is to analyze the primary rational (navigational) functions and to reconstruct technologies for the creation of ancient petroglyphs based on the gnomon of solar calendar clocks.

\section{Objects and Methods of Research}

Reconstruction of technologies for navigational use of rock carvings was developed by the authors in 2010-2017 on petroglyphs of Karelia (White Sea and Onega) and Gorny Altai (Kolbak-Tash).

The White Sea and Onega petroglyphs are located on the ancient waterways of the North (Figure 4(a)). The drawings cover rocky areas near the water, some of them were found under river sediments. More often there are images of large commercial mammals, waterfowl, people, hunting tools (bows, harpoons) and vehicles (rooks, skis). By their artistic style, petroglyphs of Karelia are close to the objects of Northern Norway, France and Korea. According to archaeological and paleogeographic data, age is estimated as V-II century BC.

Petroglyphs Kolbak-Tash (the bank of the Chuya River, the Republic of Gorny 


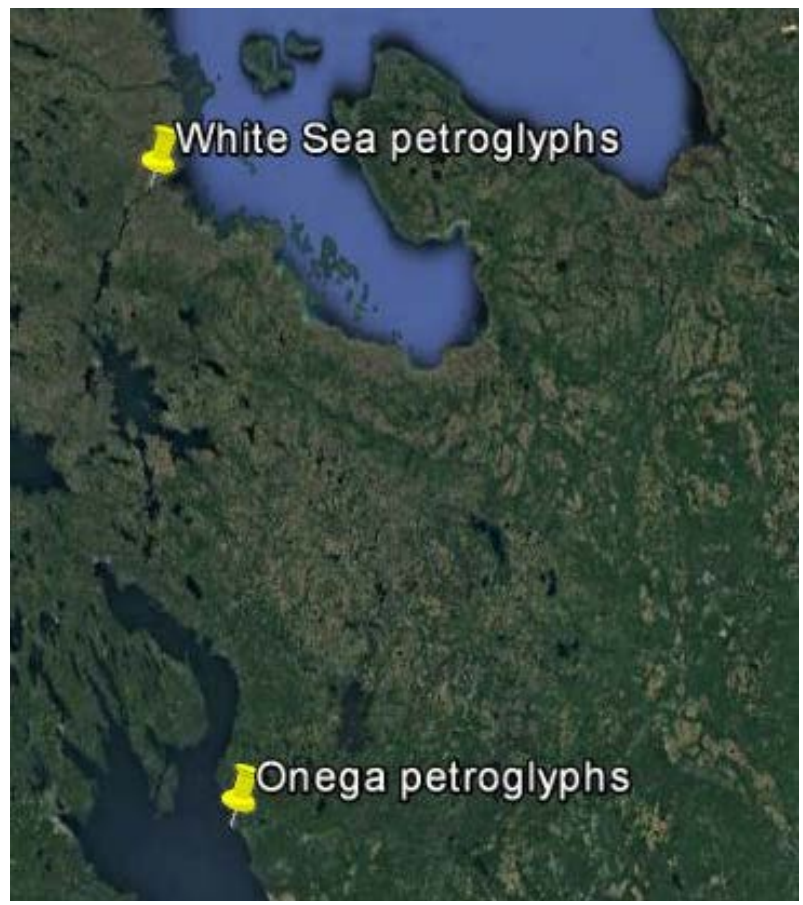

(a)

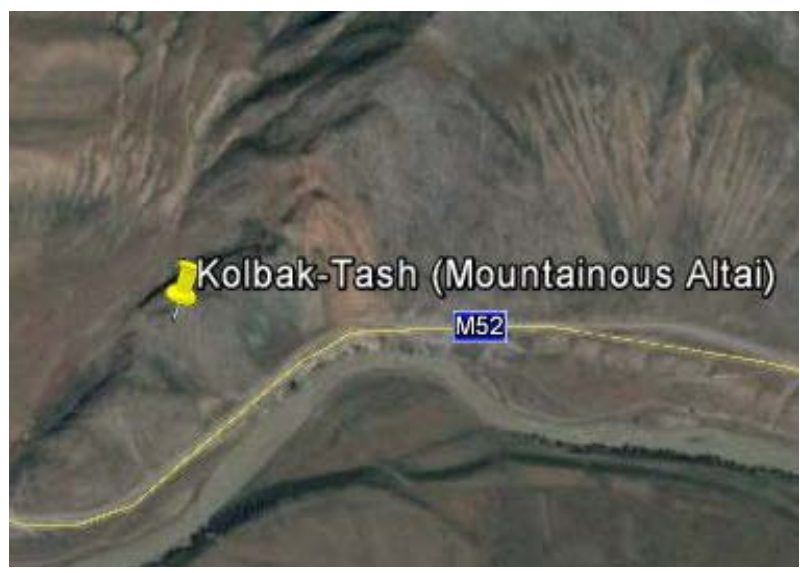

(b)

Figure 4. Location of research objects [15]. Petroglyphs are located on ancient waterways.

Altai) are located on the ancient path that connects the regions of Siberia and Central Asia (Figure 4(b)). The images of ungulates, people, wheeled wagons are dated from VI-II BC till the Middle Ages. It clearly shows that the peculiarity of ancient petroglyphs-geometric signs is covered with artistic images (for example, "lattices" are covered with figures of bulls [14]).

In the field research of petroglyphs, standard geographic methods and observations of the gnomon shadow were used. To calculate and analyze the shadow charts, the main trigonometric function, the astrocalculator, as well as the materials of scientific publications: maps, space images, depictions and photographs, were used. 


\section{Calendar in the Structure of Rock Carvings and Landscapes}

\subsection{The Navigational Capabilities of Rock Carvings}

White Sea petroglyphs. The rock wall of Old Zavravuga demonstrates the active economic development of the region in the era of the climatic optimum of the Holocene 6000 - $7000 \mathrm{BP}$, when the average annual temperatures were higher, and the productivity of ecosystems was higher than today (Figure 5).

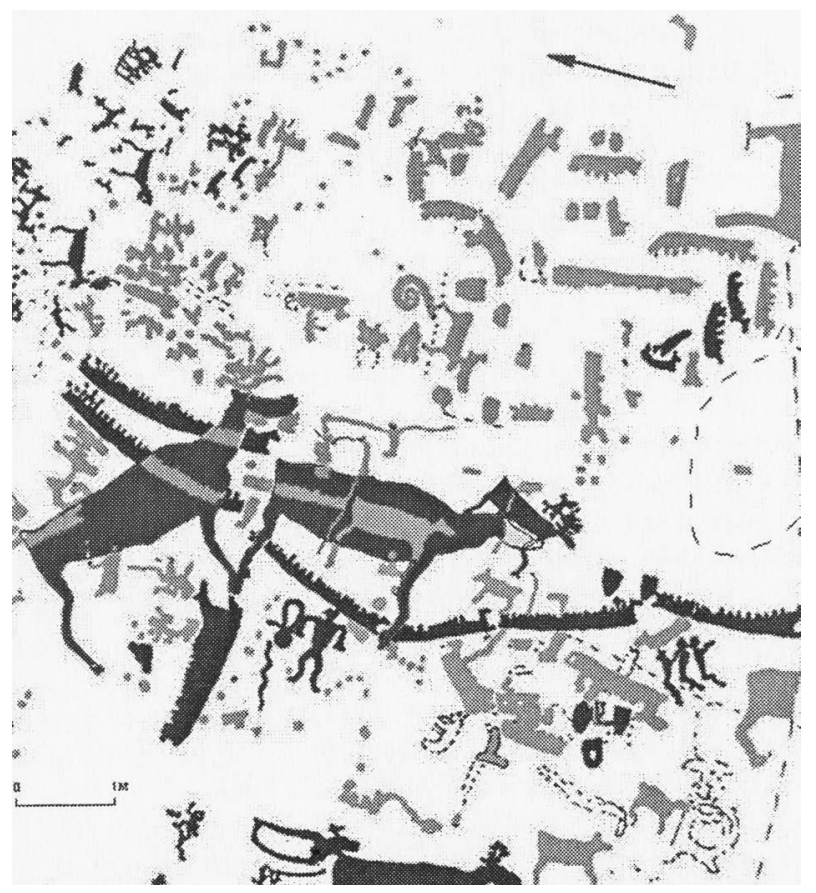

(a)

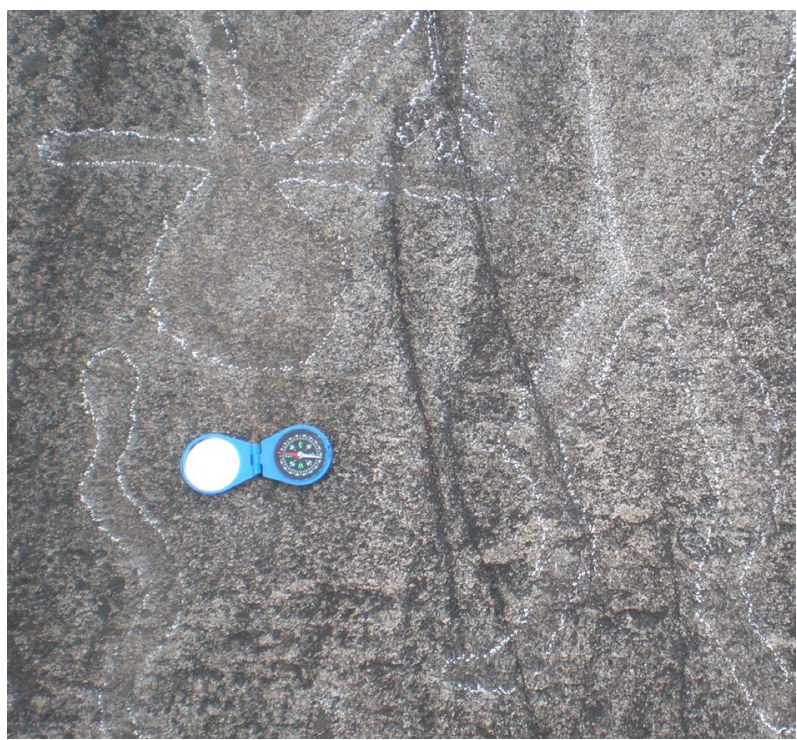

(b)

Figure 5. (a) White Sea petroglyphs (Zalavruga) [1]; (b) fragment (photo, 2010). 
When analyzing the plots of this composition (animal migration, hunting, etc.), archaeologists discussed the possibilities of a phenological calendar based on seasonal changes in the landscape and the annual economic cycle [4]. The direction of movement of deer and boats is to the south, in combination with the lowered position of the hands of the priest, suggests that the main plot of the rock panel is devoted to autumn. However, this composition can be used as a marking of an astronomical instrument, since it indicates the directions of N-S (chains of deer and ships) and W-E (human figure and other objects in the center)-objects located on the lines W-E and N-S are connected by a shadow under certain positions of the Sun.

In 2010, the object depicted next to a man, similar to the Egyptian Ankh, was interpreted by us as a calendar [10]: a bright ring-summer (polar day, sunrise), a dark ring-winter (polar night, sunset), a straight line between them-Border of seasons (analogue of the shadow chart in the days of the equinoxes). We would like to add that the object resembles an ancient anchor, where the dark part is a stone, the light one is a rope, and the straight (wooden) element is not only convenient for carrying a load together, but on deck and on land it can be used as a gnomon. It is no coincidence that the words ankh and anchor (karel "anchor") correspond.

The calendar meaning of the sign is confirmed by the image of the snake adjacent to it, the life cycle of which is clearly related to the winter/summer boundary, and the image is often used as a symbol of cyclic time.

Next to the person's figure there are plots reflecting the events of the phenological and biological calendar: above the figure there is the image of a deer with a solar spiral (possibly a deer with a umbilical cord and deer at the feet), below there is the scene of childbirth (archaeologists treat it as a "defloration scene", by analogy with the traditions of some tropical peoples). In general, the combination of plots stresses the connection of astronomical, phenological events, life cycles of a person and the biological species feeding it.

Onega petroglyphs. The largest image on the Lake Onega, called Bes, is framed by a large crack in the rock massif (Figure 6 and Figure 7). The semantics of the demon in archeology reflects the medieval Christian notions of ancestral culture: the ancient man was afraid of the surrounding nature and asked for mercy from the terrible god; The crack of the rock symbolizes the gastrointestinal tract, the sanctuary is organized in order to "feed" the demon-throwing sacrifices [16]. It is significant that the ancient pre-Christian beliefs are attributed to the market stereotype of relations ("give-and-take"), while archaic folk cultures represent a model of cooperation relations in the system "man-society-nature". For example, in the tradition of the Mari El people, it is customary to get up and work together with the Sun, and to share the harvest in autumn; the products brought to the sacred groves (for the collective meal in the festive prayers) are called gifts.

In geography, research on heritage sites is based on quantitative characteristics: 

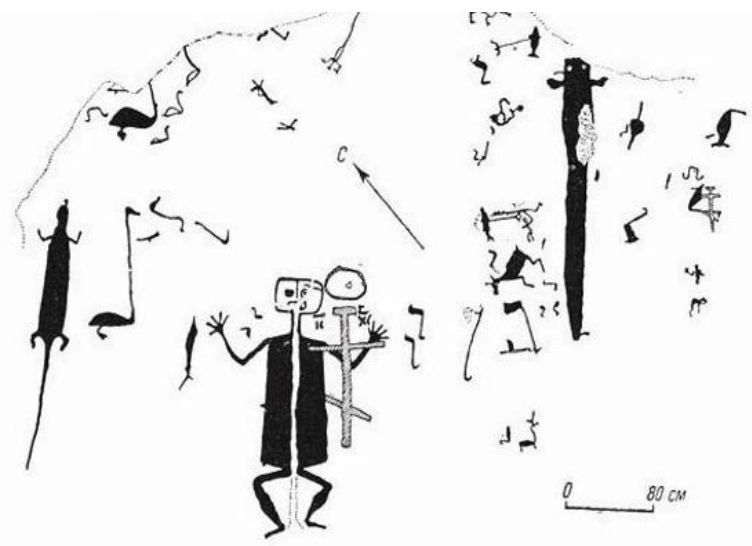

Figure 6. Scheme of petroglyphs on Cape Besov Nos [4].

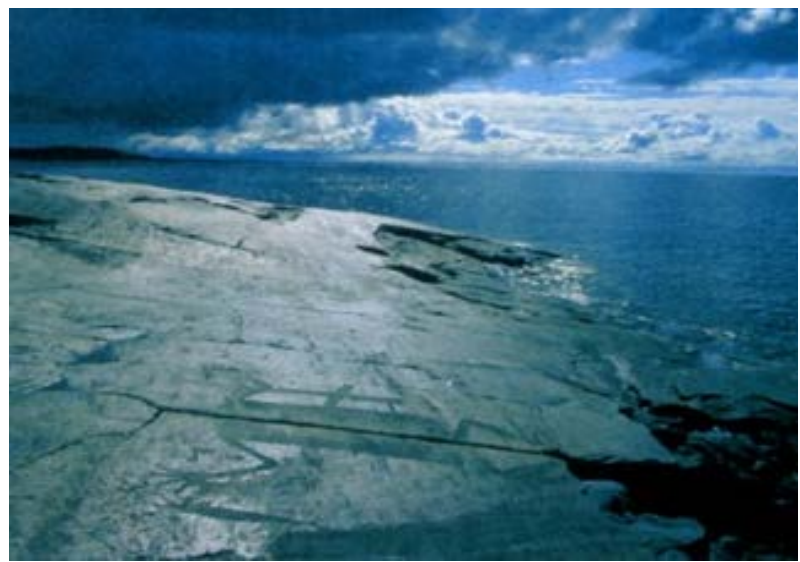

(a)

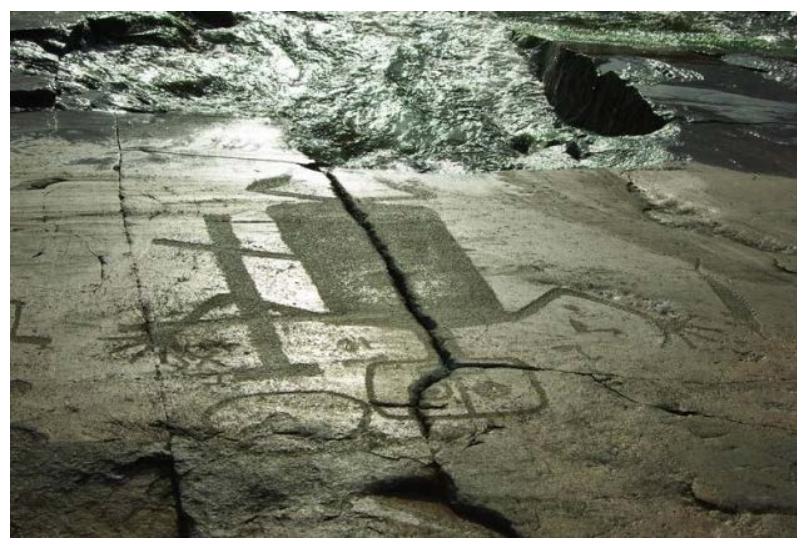

(b)

Figure 7. Photos of the rock with the image of Bes [18]: (a) the position of images on the cape provides an open horizon that does not distort astronomical azimuths; (b) "path of light" on the water and rocks cannot be the basis of the exact linear signs.

geographic azimuth (measured by a compass adjusted for magnetic declination), a calendar day (calculated for a given latitude using an online astrocalculator) 
and images (for animals: determining the biological species, its ecology and life cycle).

The Bes and nearby extended objects-the staff (corrected for the cross when it was "baptized" in the Middle Ages), have a direction of $40^{\circ}$, close to the sunrise at the summer solstice. Images of fish, animals, waterfowl fix the azimuths corresponding to late spring. The image of the fish accurately conveys the shape of the Baltic sturgeon, which rises to spawn along the Neva, Svir, further into the rivers that flow into Lake Onega in June to the present day (but only once). On this basis the Bes can be interpreted as a pointer to the place and time of fishing success.

Taking into account the impression of the image, cut by a deep crack, the picture can be considered as the first ecological "poster", tabooing/regulating the catch of fish during spawning, i.e. an example of the manifestation of environmental aspects of ancient ecological culture [17].

In the new context, petroglyphs appear as markers that fix the calendar boundaries of the hunting and fishing seasons, the prototypes of the zoomorphic zodiac and the forgotten calendar meaning of the so-called "bestial" style.

\subsection{The Creation and Use of Petroglyphs with the Help of a Gnomon}

Possible technology for determining a calendar day using a cliff with the image of Bes is the vertical installation of the gnomon in the crevice of the rock (or on the staff of Bes) and the observation of the shadow: on the line of the crack (or staff), the shadow will lie only twice a year-on the solstices: in the summer-at sunrise, in winter-at sunset. Of course, for orientation, it is preferable to use the open sector of the horizon facing the water, because it does not introduce significant distortions into the astronomical azimuths.

Drawing the shadow of a vertically installed object or own figure, any image can be created and used as a marker (linear and nonlinear, graphic or artistic) or encode the sequence of periodic events of nature that are of vital importance. To use such a mark, you must vertically place an object on it (or stand side by side) and observe the combination of the shadow with it.

Constructions suitable for this purpose are depicted on petroglyphs in the form of poles fixed in the cones of the ground (Figure 1(a)). Here, the azimuths of the sixes coincide with the days of the solstice (calendar) and with the geographical meridian (hours). The rope tied to the poles could serve to fix the plumb line and as a tool-a flexible ruler, compasses, measuring tape.

\subsection{Landscape Information Function}

The topography of petroglyphs is in good agreement with the purposes of navigation: placing by water makes them noticeable when moving, and position in a straightened valley, river mouth or on the cape provides an open horizon, necessary for astronomical observations. In addition, according to our observations, petroglyphs marked cracks of rocks and linear elements of the relief (for 
example, stone terraces) lying on astronomically significant directions. For example, on the White Sea petroglyphs one can observe the coincidence of linear elements of artistic compositions (chains of boats, deer) with the natural structure of the rock massif (its relief and fracturing), duplication of individual cracks with megalithic material (Old Zalavruga) and placement of drawings on rocks with cracks W-E (Bes trails).

The consistency of petroglyphs with W-E direction of cracks and relief is also manifested in the Kolbak-Tash massif (Figure 8). Here, the vertical plane of the

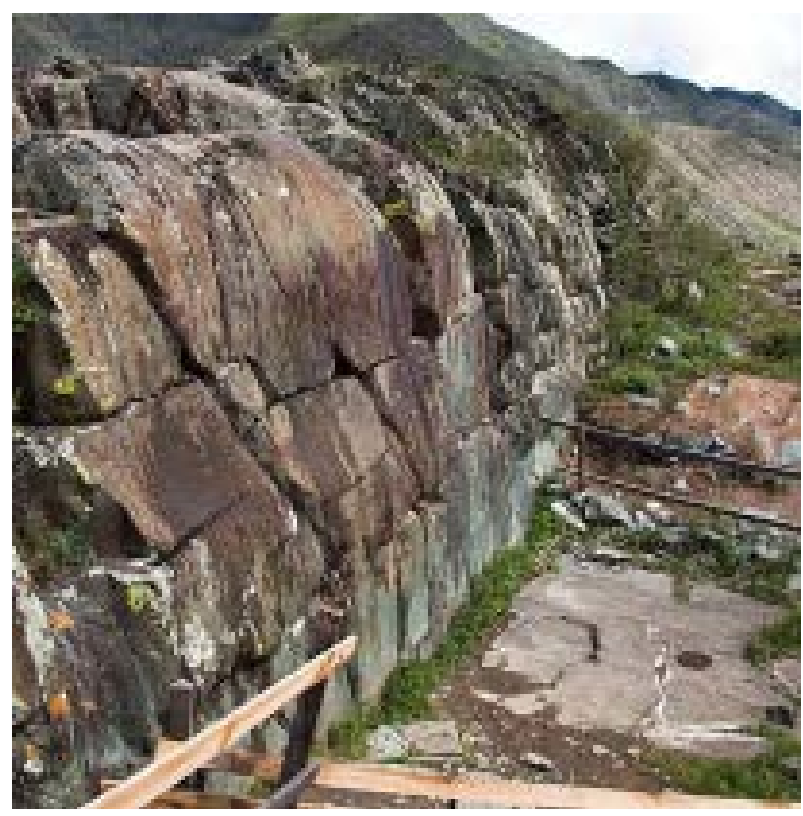

(a)

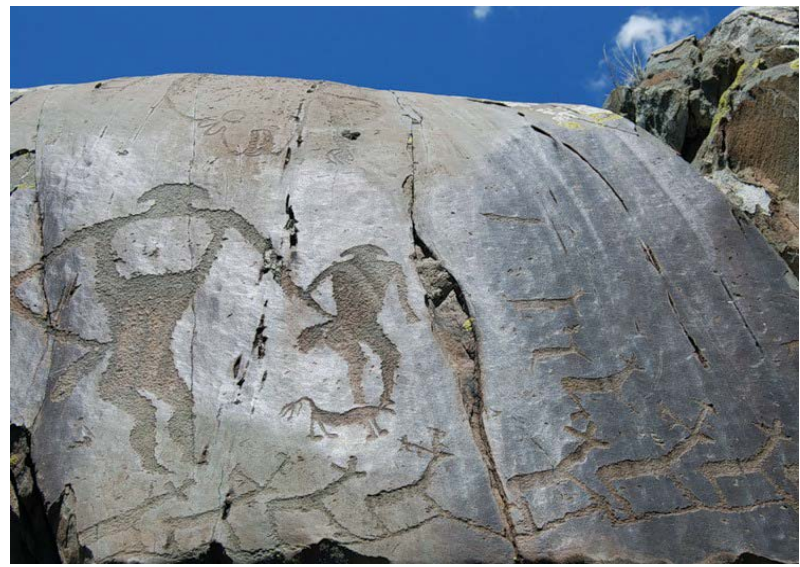

(b)

Figure 8. Petroglyphs Kolbak-Tash (Mountainous Altai) [19]: (a) an extended latitudinal strike surface is convenient for direct sighting of the sunrise/sunset on the days of the equinoxes; (b) images on the surface facing south at noon are covered by the shadow of a nearby object or figure, in the first half of the day the shadow deviates to the left, in the second half to the right. 
rock can serve as a tool for direct sighting of the sunrise/sunset, and the images are covered with the shadow of a person or an object standing by the side at noon. Thus, drawing acts as a marker, as an artificial tool, and sustainable elements of the landscape, helping to obtain and maintain vital navigation information.

Direction W-E allows to determine the days of the equinox-the border of the most contrasting halves of the year-warm and cold. This is especially important in areas with continental and extreme climate (polar and high-mountainous). Timely actions ensure adaptation-an adequate human response to a change in natural conditions. It is no accident that the days of the equinoxes are fixed by holidays in the calendars of all peoples.

\section{Conclusions}

Ancient objects that are not rationally explained by the methods of archeology and art history are interpreted today as ritual. However, on the basis of a simple astronomical tool, one can be convinced that the problems of the purpose and meaning of "ritual objects" are objectively solved through the functions of the calendar and the universal of time (forecast, stages, reproduction of life benefits and life itself).

Studies of petroglyphs with the help of gnomon solar calendars and sundials allow us to determine the algorithms for their creation and navigation use, as well as to make a number of generalizations: 1 . Available tools for navigating in the Stone Age could be sunlight, pole and stone, 2. The first simple, abstract signs represent the graphic equivalents of cyclic lighting processes and form the basis for the design of artistic drawings (images) and compositions; 3 . To create the calendar, the most stable natural material-stone was used, and there are noticeable elements of its heterogeneity-cracks and forms of relief.

The results of research on the instrumental possibilities of the spatial structure of rock carvings allow us to see in them the first step towards the creation of the dial of the solar calendars and sundials and the mathematical basis of cartographic models, the foundation of technological improvements and scientific discoveries made in the subsequent time. We can say that the use of the solar gnomon turns a rock with petroglyphs into a time scale, a school of navigation and a page of the stone chronicle of culture.

Thus, interdisciplinary studies based on geography help to identify in the monuments of heritage the rational sources of culture associated with adaptation, including the multi-faceted manifestations of deep ecological knowledge, natural activities and the cosmic mentality of an ancient person, based on the practice of astronomical orientation.

\section{Acknowledgements}

The authors express sincere gratitude to the colleagues: Prof. L. Marsadolov and Prof. E. Okladnikova for the provided materials of scientific publications with a 
detailed description of the history of studying of petroglyphs of Karelia and Altai; N. Lobanova for publishing new detailed drawings of petroglyphs and assistance in editing the text; S. Bandurko for translation of the article into English.

\section{References}

[1] Marsadolov, L.S., Paranina, G.N. and Grigoriev, Al.A. (2013) An Integrated Approach to the Study of Megalithic Heritage. Bulletin of Tomsk State University. History, 22, 72-75.

[2] Stafeev, S.K. and Tomilin, M.E. (2006) Five Thousand Years of Optics: Prehistory. Poly-Technique, St. Petersburg.

[3] Georgievsky, I.Y. and Lobanova, N.V. (2012) The Stone Book of the North. Guide to the White Sea Petroglyphs. Petropress, Petrozavodsk.

[4] Savvateev, Yu.A. (1983) Rock Drawings of Karelia. Karelia, Petrozavodsk.

[5] Lobanova, N.V. (2015) Petroglyphs of Onega Lake. Russian Foundation for the Promotion of Education and Science, Moscow.

[6] Ravdonikas, F.V. (1978) Lunar Signs in the Rock Paintings of Lake Onega. At the Origins of Creativity, Science, Novosibirsk, 116-132.

[7] Potemkina, T.M. (2010) Signs of the Moon and the Sun in Rock Paintings of Onego petroglyphs. The Urals Historical Herald, 26, 77-91.

[8] Paranin, R.V. and Paranina, G.N. (2009) Labyrinth: Orientation in the Geographical Space and Evolution of the Sign. Geo-Cultural Space of the European North: Genesis, the Structure-ra, Semantics. IV Pomor Readings on Semiotics of Culture, Arkhangelsk, 7-11 July 2008, 516-518.

[9] Paranina, G.N. (2010) Light in the Labyrinth: Time, Space, Information. Asterion, St. Petersburg.

[10] Paranina, G.N. (2011) Northern Labirinths-Gnomon and Models of Geographical Space. Elsevier. Procedia. Social and Behavioral Sciences, 19, 593-601.

[11] Paranina, A.N. (2016) Gnomon as Sours of Information on Planet Rhythms. Geomate, 10, 1815-1821.

[12] Paranina, A. and Paranin, R. (2014) Interaction of the Nature and Ancient Persons on the Coast of the White Sea. Wetlands Biodiversity, 4, 131-140.

[13] Paranina, A. and Paranin, R. (2016) The Sign as a Mapping of Geographical Space-Time: The Possibilities of Interdisciplinary Research. The Society Environment Development, 40, 95-101.

[14] Okladnikova, E.A. (2011) Lattice figures on Mount Kalbak-Tash (Mountain Altai). Archeology, Ethnography and Anthropology of Eurasia: Scientific Magazine, 47, 120-127. https://doi.org/10.1016/j.aeae.2011.11.011

[15] Google Satellite Images. https://www.google.com/earth/

[16] Paranina, G.N. and Paranin, R.V. (2009) Northern Labyrinths as Astronomical Instruments in Correlation with Samples of Mythology and Symbols of Culture. The Society. Wednesday. Development, 13, 120-134.

[17] Paranin, R. and Paranina, A.N. (2011) The Ancient Signs of the Ecological Culture of the North. Ecology-2011: Proceedings of the IV International Youth Scientific Conference, Arkhangelsk, 6-11 June 2011, 267-269.

[18] Photo of Karelia. http://www.enjoytravel.ru/Land/72/28280tur.html

[19] Photo of Altai. http://hanaltay.ru/186-petroglify-kalbak-tash-yalbak-tash.html 
Submit or recommend next manuscript to OALib Journal and we will provide best service for you:

- Publication frequency: Monthly

- 9 subject areas of science, technology and medicine

- Fair and rigorous peer-review system

- Fast publication process

- Article promotion in various social networking sites (LinkedIn, Facebook, Twitter, etc.)

- Maximum dissemination of your research work

Submit Your Paper Online: Click Here to Submit

Or Contact service@oalib.com 